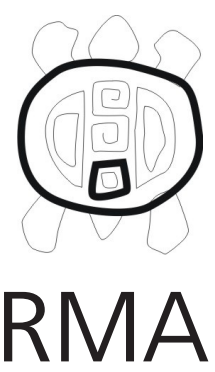

Arqueología

\title{
El patrimonio arqueológico como recurso: Políticas estatales de gestión en Tucumán y Tafí del Valle
}

\author{
Bárbara Manasse*, Sergio Carrizo** y Silvina Adris*** \\ * Instituto de Arqueología y Museo-UNT / Escuela de Arqueología, UNCa. \\ E-mail: bamanasse@gmail.com; ** Instituto de Arqueología y Museo-UNT \\ / Facultad de Filosofía y Letras, UNT. E-mail: sercarrizo@hotmail.com; $* * *$ \\ Instituto de Arqueología y Museo-UNT. E-mail: siladris@gmail.com
}

\begin{abstract}
Resumen
El territorio tucumano, en el centro del Noroeste argentino, es un área conocida por la riqueza de sus manifestaciones culturales materiales. Desde los comienzos de la constitución del Estado, Tucumán fue locus de distintas políticas y propuestas que las implicaban. Es factible rastrearlas en el accionar concreto sobre esos recursos culturales, así como también en los proyectos que se fueron planteando.

Abordaremos un primer análisis de cómo desde el Estado se fue dibujando, definiendo, en fin, construyendo el "patrimonio arqueológico" en la provincia de Tucumán, en tanto conjunto de bienes culturales materiales que representaría parte del pasado local y que, por ende, merecería recibir un trato especial a los fines de garantizar su resguardo y conservación.

Nuestro eje de estudio se centra en la materialidad indígena prehispánica del del Valle de Tafi en el Oeste tucumano indagando los diversos procesos y tomando en cuenta los diferentes actores que fueron configurando su patrimonialización en los contextos históricos, políticos y sociales de los últimos cien años. Consideramos que es un caso que puede ser paradigmático en pocos años más, tanto en lo que respecta al uso de los recursos culturales prehispánicos así como al destino de los mismos.
\end{abstract}

Palabras clave: patrimonio; políticas estatales; arqueología; materialidades indígenas; Tafí del Valle.

The archaeological heritage as a resource: State policies and management in Tucuman and Tafi del Valle

\begin{abstract}
The Tucuman region, located in the heart of Northwestern Argentina, is an area known for its wealth of cultural materials. From the earliest days of the nation, Tucuman has been a place where a wide range of policies and proposals have been advanced in relation to how these materials should be managed. It is therefore possible to review the concrete developments that have taken place along these lines, as well as the specifics of other projects that have been proposed.

Here we undertake an initial analysis of how the State has engaged in the planning, definition and, ultimately, the construction of the province of Tucuman's archeological heritage, with regard to the collection of cultural material resources. These represent a distinctive element of local history and therefore deserve special attention in terms of guaranteeing their secure curation and future preservation.

The specific focus of our study is the pre-Hispanic indigenous material culture of western Tucuman. We discuss the different processes that have taken place during the last one hundred years, taking into account the various entities involved in establishing heritage status and the associated historical, political and social contexts. We believe this is a case that may become paradigmatic in coming years, in regard to both the present-day uses of pre-Hispanic cultural resources and their long-term future.
\end{abstract}

Keywords: heritage; state policies; archeology; indigenous materials; Tafí del Valle.

El patrimonio cultural en Argentina, así como en gran parte de los países latinoamericanos y europeos, es un constructo cuya conformación está íntimamente vinculada a procesos políticos, sociales y económicos. Constituyente de este conjunto de "bienes muebles, inmuebles e intangibles", el patrimonio arqueológico se fue construyendo a partir del reconocimiento de esta disciplina -la arqueología - como herramienta adecuada para definir aquellas materialidades de las que corrientemente no se cuenta con otro tipo de información académica' ${ }^{1}$.

En Argentina, como en gran parte del continente suramericano, el patrimonio arqueológico suele

\footnotetext{
1 Si bien la arqueología, como disciplina científica, avanza sobre períodos históricos, a nivel de la definición y gestión del patrimonio cultural también intervienen otros profesionales de áreas como la arquitectura, las artes plásticas o la historia.
} 
comprender, en especial - aunque nunca exclusivamente - a las materialidades del pasado indígena, y particularmente, de su pasado prehispánico. Desde los albores del siglo XX el Estado nacional - junto a los científicos y a los sectores sociales más representados en el gobierno - comienza a delinear un marco legal por el cual esas materialidades pasan a ser concebidas como bien público. Ya desde las primeras propuestas jurídicas el patrimonio arqueológico es concebido como un recurso que, más allá de funciones claramente políticas, serviría para informar e ilustrar al público desde programas educativos y de las exhibiciones en museos (Endere 2007).

El Estado nacional en la actualidad - en una propuesta que aún no supera una visión monolítica, homogénea de su población - sostiene que el patrimonio arqueológico está conformado por las cosas muebles e inmuebles o vestigios de cualquier naturaleza que puedan proporcionar información sobre los grupos socioculturales que habitaron el país desde épocas precolombinas hasta épocas históricas recientes (los últimos 100 años) ${ }^{2}$. Este concepto define desde el ámbito jurídico lo patrimonializable, aquello que debe ser protegido, pero, a la vez que instala un sentido de la materialidad indígena, establece parámetros de validación, como se lee en la definición propuesta por la legislación tucumana vigente:

"El Patrimonio Arqueológico está constituido por los bienes inmuebles, vestigios, restos y objetos que evidencien manifestaciones humanas que tengan los valores propios del patrimonio cultural y que sean susceptibles de ser investigados mediante metodología arqueológica." Art. $3^{\circ}$ Inc. b de la Ley 7.500 de la provincia de Tucumán.

Aunque actualmente estos presupuestos son cuestionados por voces nuevas ${ }^{3}$, somos los científicos los que quedamos a cargo de "producir" estos bienes culturales a través de nuestra investigación - arqueológica, pero también desde otras disciplinas como el folklore - y de la confirmación o determinación de su valor. Como ya lo señalara una de nosotras años atrás, hemos ido imponiendo nuestra particular concepción del pasado indígena local, nuestra interpretación de su materialidad (Manasse y Rabey 1992). La arqueología, en América en general, se fue convirtiendo en "la" palabra autorizada para construir el pasado de cualquier pueblo, para construir su historia (Benavides 2005; Endere y Curtoni 2003; García Canclini 1999; Mamani Condori 1989).

Sin embargo, y como lo desarrollaremos más adelante, no ha sido ni es la única protagonista a la hora de brindar los fundamentos para delinear las políticas de

\footnotetext{
${ }^{2}$ Art. $2^{\circ}$ de la Ley Nacional 25.473 y su Decreto Reglamentario.

3 "Nuevas", en tanto recién se las comienza a escuchar en el plano estatal, reconociéndose su derecho a la intervención en las decisiones que competen a su presente y futuro. Nos referimos a los pueblos originarios, pero también a cualquier otro grupo social, cultural vinculado históricamente con alguna materialidad que se quiera poner en valor.
}

gestión de estas materialidades que constituirían el patrimonio arqueológico. No se establece una relación lineal, direccional o causal entre la arqueología y el Estado. En un importante cruce de intereses, en cierto modo soslayando su valor cultural, la materialidad del pasado indígena regional también se fue constituyendo en recurso económico. Si bien argumentando en favor de la cultura, los restos materiales prehispánicos son concebidos como un importante recurso de explotación turística. En este marco, los parámetros de validación son otros, la valoración se establece según todo un conjunto diferente de criterios.

Finalmente queda otra mirada, otra concepción, que se vincula desde la práctica y generación mismas de estas materialidades: la de las sociedades nativas, los "pueblos originarios". Las reformas realizadas en el marco jurídico nacional y provincial los definen como nuevos protagonistas en este campo que estamos procurando analizar. Una nueva concepción, otra vez más cultural, pero también claramente política, se instala redefiniendo las materialidades de su pasado como otro tipo de recurso.

Nos interesa, en particular, analizar ese entramado de construcciones e implementaciones de políticas que se fueron desarrollando tanto desde el aparato del Estado, como en el marco del campo intelectual, de la comunidad científica - en particular, la arqueológica - y de los sectores populares, indagando las implicancias sobre las materialidades del pasado en esta provincia - y en particular en el Valle de Tafí-, apuntando a una mejor comprensión de las dinámicas y las construcciones simbólicas de las mismas.

Planteamos además que la ambición de estas políticas y prácticas académicas no siempre descansan en mutaciones directa e inmediatamente visibles sobre la sociedad y sobre la materialidad analizada.

\section{Los recursos culturales / arqueológicos en Tafí del Valle, Tucumán}

En primer lugar, y a modo de breve explicitación del planteo que proponemos, retomaremos algunos conceptos que orientan nuestras investigaciones. Compartimos la propuesta de Bonfil Batalla (1993: 21) cuando sostiene que,

"...cuando hablamos de patrimonio cultural de un pueblo, a lo que nos estamos refiriendo es, precisamente, a ese acervo de elementos culturales, tangibles unos, intangibles los otros, que una sociedad determinada considera suyos y de los que echa mano para enfrentar sus problemas, [...]; para formular e intentar realizar sus aspiraciones y sus proyectos; para imaginar, gozar y expresarse..." .

$Y$ es justamente cuando se "echa mano" de ese acervo, cuando se transforman en recursos - de orden 
estrictamente cultural o, también, político y económico Ahora, respecto ya, más específicamente, al patrimonio arqueológico decíamos que el mismo suele estar comprendido, en nuestras regiones, por materialidades del pasado indígena local ${ }^{4}$. Si bien el pasado de estas sociedades no se ve tan solo reflejado en sus materialidades, el espacio y los paisajes construidos son mayormente investigados -conocidos, representados - a partir de ellas 5 .

Ahora, ¿de qué sociedades indígenas estamos hablando? La región oriental de los valles serranos tucumanos ha sido habitada desde hace más de dos mil años atrás; y, seguramente, fue espacio de explotación por sociedades de economía extractiva aún miles de años antes (Somonte 2005). Las discusiones sobre si el Valle estaba habitado en tiempos de la conquista, y de ser así, por quiénes, aún están vigente (Bixio y Berberián 1988, Manasse 2006). Más allá de ello, son bastante recientes los procesos de reconocimiento como pueblos originarios en el Valle de Tafí por parte de su población nativa, dando lugar a la revisión de viejos presupuestos, evaluando percepciones y configurando nuevas propuestas (Arenas 2003; Manasse y Camerlingo 2007; Manasse 2008).

Los pueblos que hicieron del Valle de Tafí su hogar en los alrededores del inicio de la Era Cristiana (EC) período Formativo - son conocidos actualmente por manifestaciones materiales diversas. Algunas de ellas, como es el caso de los menhires, hicieron famoso a Tafí. Se trata de sociedades que desarrollaron un estilo de vida agro-pastoril, fuertemente vinculado a la tierra y a los ancestros; en la arqueología se las conoce como "Cultura Tafi"6. Con este nombre se fue identificando a los que serían considerados como los únicos pueblos indígenas autóctonos que, además, no habrían llegado a habitar esta región más allá del primer milenio de la EC.

Cultores de complejas creencias manifestadas en los monolitos, pero también, en un mundo simbólico reflejado en piezas en piedra, cerámica y metal ${ }^{7}$, ocuparon todo el Valle y sus alrededores. Cientos de recintos circulares en piedra serían testimonio de esta etapa de la ocupación humana de Tafí. Se los encuentra en todas partes: en el fondo del valle, junto a los cursos de agua, en los faldeos

\footnotetext{
${ }^{4}$ Desde el enfoque que abordamos, procuramos alejarnos de conceptos tales como los de "restos arqueológicos" o "evidencias arqueológicas" que, aunque vigentes en el uso cotidiano -académico, jurídico y de la sociedad en general- remarcan el requerimiento de la competencia exclusiva de los especialistas en la investigación arqueológica para la definición y/o valoración de lo que se deberá atender/proteger (Vg. Curtoni 2004; García Canclini 1993; Shanks y Tilley 1992).

${ }^{5}$ La Ley Provincial de Protección del Patrimonio Cultural de Tucumán ( $N^{\circ} 7500$ ) estipula una categoría específica para lo que allí se denomina "paisajes culturales", pero ellos no se encuentran claramente reflejados en el Sistema de Protección creado por esta Ley.

6 Definida por Sommer a mediados del siglo XX (Bennett, Bleiler $y$ Sommer 1948).

7 Los objetos asociados son variados, pero pocas veces han Ilamado realmente la atención de la gente. Ello también se ve reflejado y tiene su expresión en las exposiciones de los museos.
}

montañosos, en sus cumbres y en las quebradas que articulan hacia el Este con la llanura tucumana y por el Oeste hacia los valles semiáridos occidentales.

El "patrón margarita"8, junto a los menhires, algunas andenerías y el montículo de Casas Viejas en el sur del Valle, pasaron a ser los restos arqueológicos por excelencia de este valle intermontano. Aquellos monolitos son interpretados de maneras muy diversas y son uno de los referentes más claros del rol social, político, pero también económico, de los restos arqueológicos en nuestra sociedad (Manasse y Arenas 2001; Mastrángelo 2001). El Formativo constituyó hasta hace muy poco tiempo atrás el eje de las investigaciones arqueológicas. La "cultura Tafí" es el referente clásico del pasado prehispánico local, Casas Viejas, con su montículo en el sur del Valle de Tafí, y La Bolsa, en Carapunco, al norte, se transformarán en sitios emblemáticos (Manasse 2002 a).

Sin embargo, hay otros elementos que tienen un lugar particular como ejemplares representativos de los tiempos prehispánicos, por caso, morteros y estatuillas grabadas en piedra - parte de la parafernalia de los primeros siglos de la EC -, y las imponentes urnas de la alfarería Santamariana o algunas piezas aún más tardías, de filiación inca ${ }^{9}$. Y es con éstas que nos vamos alejando del Formativo para entrar de lleno en una época que solo últimamente es investigada desde la arqueología (Manasse 2007; Montini 2008; Patané Aráoz 2009). Estas evidencias materiales, junto a otras aún más recientes, son testimonio de pueblos que habitaron Tafí en el segundo milenio de la EC. Más allá de la narrativa histórica oficial que sostiene la inexistencia de población para la época de la invasión española, cada vez es más elocuente su falta de veracidad (Manasse 2002 a).

Desde una mirada disciplinar se observa, entonces, la existencia de sesgos en la información que involucran ciertos tiempos y cierto tipo de materialidades; y que, obviamente, tienen su repercusión en los relatos sobre el pasado prehispánico y colonial del Valle.

Actualmente en Tafí hay un énfasis creciente en la valoración de áreas con evidencias arqueológicas, que va más allá de los menhires. Se trata de un interés claramente económico, desde el cual se buscan nuevos espacios para el usufructo turístico ${ }^{10}$. Dejando a un lado la Reserva Arqueológica Privada de La Bolsa, que prácticamente se encuentra cerrada al público, los sitios que son visitados por turistas carecen de investigaciones científicas previas y de planes de gestión adecuados para su preservación.

\footnotetext{
8 Patrón de asentamiento formativo que tiene su carácter conspicuo en recintos circulares.

${ }^{9}$ Existe un importante tráfico de todo este tipo de piezas; y, paradójicamente son las que sí son mostradas en los museos.

10 En el marco de un Turismo Cultural o Alternativo se abren a la explotación turística espacios como el montículo de Casas Viejas, que es visitado cada vez más como un lugar de mucha "energía espiritual y planetaria".
} 
Por otro lado, y en contraste con lo descrito anteriormente, con el importante desarrollo del negocio inmobiliario se está produciendo una fuerte afección sobre toda esa materialidad: se están destruyendo asentamientos indígenas completos, se rompen decenas de piezas cada semana, así como estructuras arquitectónicas de funcionalidad diversa.

Recientemente las Comunidades Indígenas ${ }^{11}$ locales se han propuesto intervenir en la gestión de estos (sus) recursos culturales, poniendo en valor y actualizando sentidos en una serie de áreas con materialidades indígenas prehispánicas. Se trata de áreas que son evaluadas conjuntamente con nuestro equipo de investigación. Es una situación completamente novedosa, que va revirtiendo un desconocimiento y desinterés tradicionales ancladas en gran parte de la población nativa local (Manasse y Camerlingo 2007).

Esta breve enumeración y caracterización apunta a proporcionar una primera mirada a la compleja situación que caracteriza al patrimonio cultural indígena / arqueológico de la región. Es nuestro objetivo avanzar en la comprensión de los procesos que intervinieron y en cierto modo la fueron generando y, si bien centraremos nuestro análisis en las políticas delineadas desde el Estado (nacional y provincial), procuraremos ir abordándolas en su articulación con los intereses de los demás sectores sociales arriba ya delineados.

\section{Las políticas del Estado frente al patrimonio arqueológico de Tucumán}

Tomando como base la propuesta de Ozslack (1982), concebimos al Estado como una instancia máxima de poder político que materializa un aparato burocrático - institucional, y que es resultado de un decurso histórico, cuyo proceso no es lineal ni mucho menos las opiniones que lo formaron. Por lo tanto la estatidad es un aspecto constitutivo de fuerzas y elementos múltiples y heterogéneos.

\section{Inicios de la Patrimonialización: un menhir en plena ciudad}

En el marco de los festejos por el centenario de la independencia el entonces gobernador Padilla ordena, por decreto, que Ambrosetti baje un menhir para integrar parte de la parafernalia alegórica en el recién creado Parque 9 de Julio (Mastrángelo 2001). Este monolito pasará a ser, como lo señala esta autora, el único representante de la producción material del pasado indígena en un espacio diseñado para parecer "moderno y civilizado". Los relatos de la gente de Tafí, que aún recuerda este traslado del monolito a través de la voz de los mayores, dan cuenta de su relevancia en la memoria colectiva local. Ello, más allá de que, según

\footnotetext{
11 Comunidades Indígenas inscriptas en el Registro Nacional de Comunidades Indígenas, que hoy comprenden un sector importante de la población nativa.
}

las aseveraciones sugestivas de Ambrosetti, los mismos habrían sido elaborados por una antiquísima civilización perdida, que no tendría relación histórica ni cultural alguna con los pobladores del Valle de la conquista (Ambrosetti 1897 a).

La materialidad indígena fue objeto de atención temprana en la provincia y la nación. El interés científico, y de aquellos sectores sociales vinculados más estrechamente al gobierno de turno, se rastrea con claridad a mediados del siglo XIX, en los albores del Estado Nacional. El pasado indígena y sus materialidades comenzaron a ser estudiados, analizados y pensados en función de preceptos de alteridad y de cierto nacionalismo, más siempre en el marco de un claro alocronismo ${ }^{12}$. En un complejo contexto social, económico y político, ellos se fueron patrimonializando.

Con el cambio de siglo el Estado Nacional irá definiendo las políticas que le permitan apropiarse de las materialidades indígenas prehispánicas y del pasado que significan. En 1907 se promulga la Ley Nº 3.799 en el marco de la cual se adquiere la colección de antigüedades calchaquíes de Zavaleta, la que será destinada al Museo Nacional ${ }^{13}$. Como lo expresan Endere y Podgorny (1997), la misma Ley $N^{\circ} 9080$ se sanciona como una estrategia para llevar al dominio público las colecciones privadas que hacia finales del siglo XIX detentaban esas manifestaciones culturales que ayudarán a construir la nación. Formalmente, la materialidad indígena prehispánica, ya configurada como "ruinas y yacimientos arqueológicos", fue patrimonializada por el Estado a través de aquella ley, estableciéndose a la Nación como su propietaria y, también, el carácter público de esos bienes, status especial reconocido en razón de un valor científico que deberá ser interpretado según el significado de la ciencia para la restauración nacionalista (Endere y Podgorny 1997).

Una de las expresiones importantes de este proceso se observa en la musealización de las representaciones materiales del pasado. Los museos que se fueron creando, asociados a los procesos de especializaciones disciplinares, aparecen como lugares de producción de conocimiento científico. Junto a las sociedades científicas, muchos de ellos surgieron en el seno de las sociedades eruditas metropolitanas y provinciales como espacios de visualización y de construcción de discursos necesarios a la conformación del perfil de la Nación.

Ahora, si bien los museos coadyuvaron a desplegar, a exponer la materialidad indígena, es claro que, como ya lo señala Podgorny (2005), es necesario indagar profundamente la vinculación existente entre éstos y el Estado. Más allá de una cuestión que se presenta entonces sumamente compleja, creemos que estas

\footnotetext{
12 Fabian 1983.

13 Esa colección cuenta con varias piezas provenientes del Valle de Tafí y de la provincia de Tucumán en general.
} 
"catedrales de la ciencia" generaron esquemas simbólicos y relaciones entre las cosas, las palabras y las personas.

Durante la gobernación de Padilla mientras se instalaba el menhir "Ambrosetti" en el recién creado Parque 9 de julio se fundaba el Museo de Historia Natural (1915). Schreiter, curador del museo, fue armando las colecciones a la manera y con los objetivos ya delineados para esta época ${ }^{14}$. Siguiendo estos lineamientos, el trabajo netamente descriptivo que realizara sobre los menhires de Tafí del Valle es ilustrativo de la perspectiva teórica positivista desde la cual orientaba su práctica científica (Schreiter 1928).

Estas primeras décadas del siglo XX verán crecer en Tucumán la vida científica desde las instituciones que, a partir de aquel primer Museo, se fortalecerán con la nacionalización de la Universidad de Tucumán (1921) y, luego, la creación del Instituto de Etnología (1928). Sin embargo, en un marco de creciente proletarización de las poblaciones nativas se fue perdiendo el objeto de estudio: el carácter del "otro". Metraux (1928) advertía sobre la urgencia de obtener material etnográfico de esas naciones ${ }^{15}$. De hecho, los estudios afrontados desde el Instituto de Etnología (UNT) priorizaron el contenido de los datos que puede aportar la comparación con los mudos testimonios de las evidencias arqueológicas (Carrizo 2004). La investigación científica (etnográfica y arqueológica) se centraría en el salvataje de lo que "quedaba" de las poblaciones "primitivas" en nuestro país. Tafí, considerado exclusivamente criollo, no entrará en esas agendas.

Para fines del siglo XIX el naciente Estado Argentino estaba dirigido por una elite criolla que se encontraba en plena coincidencia y ligazón con Europa y con sus intereses económicos dentro del sistema capitalista internacional. En el plano simbólico desde el Estado Argentino se buscó generar identidad a través de imágenes societales concretas.

Por entonces Tucumán está buscando posicionarse frente a la pampa húmeda, viviendo además un proceso de modernización devenida de la conformación de la industria azucarera. Las disputas por los espacios de poder económico y político a nivel nacional llevarán a luchas en el plano cultural. En esta época comienzan a oírse las primeras reivindicaciones del provincialismo norteño y tucumano como entidad cultural (Mastrángelo 2001).

\footnotetext{
${ }^{14}$ Schreiter - quien se había especializado en las Ciencias Naturales se presenta al Primer Congreso de la Sociedad Argentina de Ciencias Naturales con una muestra del Museo de Historia Natural, que contaba con piezas arqueológicas de los valles de Santa María, El Cajón y Hualfín (Carrizo 2004).

15 "La práctica de la Arqueología se destinaba a 'resucitar la civilización de las regiones en que las poblaciones primitivas van desapareciendo', las comunidades etnográficas se encontraban en proceso de arqueologización y la Etnografía moderna era un complemento de la Arqueología en la estrategia de conocimiento de aquellas." (Arenas 1998: 125.)
}

El Estado, así como las élites locales, fue sirviéndose de las imágenes proyectadas por viajeros y naturalistas que circularon por este territorio. Entre los muchos exploradores que visitaron este suelo podemos recordar a Burmeister, Lorentz o Stelzner. Estos viajeros, de algún modo contribuyeron con la idea de exotismo, propio de tierras lejanas, y con el despertar de una curiosidad por la fauna y vegetación peculiares de estas regiones, e incorporaron el pasado representado en las "ruinas arqueológicas", como parte de esta variada y particular "naturaleza".

Por su parte, los resultados de las expediciones científicas realizadas por los profesores del Colegio Nacional de San Miguel de Tucumán, Liberani y Hernández fueron útiles a la creación de lo que uno de nosotros ha denominado como una territorialidad provincial (Carrizo 2010). Sus descripciones aportaron a la conformación de relatos históricos que partieron de la idea de civilizaciones en ruinas o directamente extinguidas, dando inicio a las prácticas arqueológicas locales. Estos precursores produjeron un informe del viaje realizado en enero de 1877 a los valles Calchaquíes, desplegando toda una serie de imágenes de un territorio cargado de "mudas ruinas".

La materialidad indígena, su pasado, fueron utilizados para lograr en la población lealtades para con la nación; se buscó materializar los nexos entre el pasado histórico, un territorio determinado y la sociedad argentina.

En este contexto podemos insertar los trabajos de Quiroga en la provincia de Tucumán. Este intelectual articuló su accionar jurídico, político y literario con la ciencia, con la arqueología, el folklore y la historia. Su perspectiva de nación fue contrapuesta a la del puerto bonaerense -expresada en las ideas de Sarmiento, por ejemplo-: el indígena americano conforma parte de ella. Así, "La historia de las razas americanas es, pues, nuestra propia historia; su tradición, la tradición de nuestra tierra y de nuestra raza." (Quiroga 1892: 38).

Más allá de las obras clásicas de este autor, merece comentarse el texto que refiere a sus investigaciones en los valles interandinos que colindan inmediatamente al Norte con el de Tafí (Quiroga 1899). Allí expresa admiración por la riqueza de las manifestaciones en estas regiones, de la "grandeza salvage [sic] de esta región tucumanense" (Idem supra: 8). Se trata, sin embargo de una riqueza perteneciente a poblaciones muy antiguas, que nada tienen que ver con las que los españoles encuentran al conquistar estas tierras. Al igual que Ambrosetti, Quiroga va a sostener que estas evidencias del pasado no fueron realizadas por los pobladores de la época de la conquista: "...una raza poderosa habitó estas montañas, raza que no puede ser la Calchaquí, pues más que establecido parece estar ya, que los Calchaquíes no era un pueblo laborioso, sinó unos bárbaros de muy escasa cultura..." Quiroga (1898: 37). Y como lo sostiene en su clásica obra "Calchaquí" (1892), los Calchaquíes solo hace unos 
pocos siglos se habrían asentado en estas tierras, luego de destruir a sus antecesores ${ }^{16}$.

La ciencia de esta época, típicamente positivista, alcanzará objetivos acordes a los intereses de los sectores sociales en el poder: trazar los lineamientos de la Nación Argentina. Para este proyecto, fuertemente nacionalista, los pueblos nativos solo tendrán el lugar de "pasado" (Arenas 1989-90). En este sentido, González advirtió en la producción científica arqueológica de Ambrosetti," ... el divorcio que existía entre la idea que él tenía de los restos arqueológicos que estaba excavando y la que tenía con respecto de aquel indio de carne y hueso que era su contemporáneo y cuyos restos excavaba. No ve el vínculo histórico y social que existe entre unos y otros. Solo le anima su interés cientificista." (González 1989: 113).

Ambrosetti presentó al mundo científico en 1896 la existencia de los menhires y con ello inaugura un estilo de estudio, que perdura prácticamente hasta el día de hoy en el Valle de Tafí y que hace de estos monolitos y sus hacedores el eje de la arqueología local y de la gestión del patrimonio arqueológico. Al igual que otros investigadores de la época, un argumento significativo para la construcción del pasado regional es el de la inexistencia de lazos culturales e históricos con los pobladores conquistados por los europeos del siglo XV y XVI (Endere 2007; Mastrángelo 2001). Argumento útil no solo a la hora de definir la gestión de esos recursos, sino también de poner en tela de juicio otros derechos indígenas, como el de la tierra (Manasse y Arenas 2010).

El Valle de Tafí será sucesivamente "visitado" por diferentes investigadores que, como el mismo Ambrosetti (1897), o más tarde Bruch (1911), tienen por objetivo reunir datos sobre las antiguas poblaciones indígenas y obtener materiales que engrosen diversas colecciones. Ya tempranamente aparecen algunos elementos fuertes que van a contribuir a una definición identitaria del pasado indígena local que enfatiza en el carácter foráneo los pueblos hallados en tiempos de la conquista ${ }^{17}$. El pasado grandioso era de un pueblo que ya no existía por entonces y que será reflejado en los monolitos; varios investigadores centrarán sus estudios en ellos.

La población del Valle, que es por entonces básicamente rural y con un componente casi exclusivamente nativo, servirá ocasionalmente de peones en sus trabajo de campo (cfr. Lafone Quevedo 1899). Indios puros, según lo describe Ambrosetti a fines de este siglo XIX, " ...y poco acostumbrados a ver gente civilizada, nos miran

\footnotetext{
16 Rodríguez (2008) refiere a esta operación discursiva como la "distopía calchaquí": se distingue un pasado indígena glorioso - del cual son producto las imponentes evidencias arqueológicas - del presente indígena, poco menos que despreciable. Estos últimos son los herederos de los calchaquíes salvajes que invaden los valles, destruyendo todo a su paso. Como lo señala esta autora, ello le otorgaría legitimidad a la pretensión española de estas tierras.

17 Cf. Borda 1938, Bixio y Berberián 1988, por ejemplo.
}

con desconfianza, y me parece adivinar en sus caras inexpresivas, la extrañeza que les causa esta invasión..." (1897 b: 302).

\section{Promediando el siglo XX: conceptualizaciones del Patrimonio}

En la primera mitad el siglo XX Argentina se ve enredada en los procesos sociales y políticos que tuvieron eje en las guerras de Occidente. Los procesos migratorios también incidieron en un resurgimiento nacionalista, en particular en el ámbito cultural. Hacia la década del '40 se manifiesta un expreso interés del Estado por el patrimonio histórico (Manasse y Korstanje 2010).

Desde lo arqueológico, continúa el énfasis en la identificación y definición de territorialidades, de la demarcación de etnicidades, aunque algunos investigadores procuraran sortear estas últimas ${ }^{18}$. Se busca ordenar las materialidades indígenas prehispánicas de tal modo de comprender el pasado desde sus distribuciones. El valle de Tafí se constituyó en locus de una "cultura" homónima (Bennett, Bleiler y Sommer 1948). La región pedemontana oriental, en particular al Norte de la provincia, será segregada como un espacio cultural completamente diferente. Con los trabajos de Schreiter y Metraux sobre "Candelaria" se instala la idea de que del lado oriental de los cordones montañosos que lindan con la llanura habitaban otros pueblos, que difieren completamente de los diaguita-calchaquí.

Otro acercamiento diferente lo podemos observar en las investigaciones realizadas desde el recientemente creado Instituto de Estudio Geográficos (UNT). Por un lado, Barbieri de Santamarina (1945) realiza un análisis histórico del uso del espacio y los recursos del Valle de Tafí desde los tiempos prehispánicos, brindando una nueva mirada a las espacialidades, a los territorios indígenas. La geógrafa recalca la relevancia de Tafí en el contexto regional, presentándolo como un área de contacto de diversos grupos étnicos de la región. Y destaca, en una apreciación particular de los estudios arqueológicos previamente realizados en la zona, que el valle estaría ocupado por población diaguita. Sin embargo, la autora sostiene que esta población habría emigrado antes de que llegaran los españoles a este valle. Aquella apreciación de la existencia de pueblos diaguita ocupando el Valle de Tafí, también es propuesta por la geógrafa Santillán de Andrés, en su estudio de las poblaciones indígenas del Valle (1951).

Por otro lado, cabe destacar que Barbieri de Santamarina decide relevar arqueológicamente la zona de La Quebradita, remarcando la relevancia de este estudio ante la destrucción definitiva de sus "ruinas" por el avance urbano que comienza a manifestarse desde la apertura

\footnotetext{
${ }^{18}$ Ver Scattolin (2006).
} 
de la ruta provincial $\mathrm{N}^{\circ} 307^{19}$.

Ahora, desde el Estado, con el gobierno peronista observamos cambios de relevancia. Se renuevan parámetros jurídicos que establecen que debe ser el Estado el que ejerza la tutela de las riquezas artísticas e históricas que forman parte del patrimonio Cultural de la Nación ${ }^{20}$. Con la Reforma Universitaria del '47 se define la incumbencia del Estado hasta en aquellos espacios que habían construido su autonomía ya algunas décadas atrás. Se establecen nuevas prioridades científicas que estarán supeditadas a cuestiones vinculadas a las necesidades productivas del estado y la academia. En lo que respecta al Instituto de Antropología (UNT), se hace énfasis en la Antropología Física a los fines de realizar estudios poblacionales y de potenciales recursos para el desarrollo productivo del país. En cuanto al mundo indígena, las propuestas y los discursos pueden encuadrarse en el alocronismo de Fabian (1983). Ello es más notable con la gestión de Males, quien también cumplía funciones en el Instituto Étnico del Norte Argentino, desde el cual y para el cual se aportarán datos antropo-biológicos que permitan avanzar en interpretaciones sobre la vinculación raza - cultura.

Los años sesenta se caracterizaron por la gestación de una concepción del patrimonio cultural, que a partir de una creciente valorización económica, encuentra en el usufructo turístico su mejor carta de presentación (Manasse y Korstanje 2009). Ya en los primeros trabajos de González en el Valle de Tafí y, claro es, en algunas de las políticas que se van delineando desde el Estado y la Academia, se hace evidente un progresivo cambio en el paradigma de los sentidos de la materialidad indígena prehispánica. Tanto González -como investigador externo a la provincia - como Krapovickas - director de los museos del Instituto de Antropología (UNT) -, fueron realizando propuestas de una gestión que además del sentido cultural incorpore el valor turístico. Más ello, implicando exclusivamente a los menhires; el resto, por caso la zona de La Quebradita otra vez, está sujeto a las afecciones por el crecimiento urbano.

En 1965 se elaboró un Plan de Trabajo Interdisciplinario sobre el Valle de Tafí a pedido de la Secretaría de Cultura de la Nación, en colaboración con el Instituto de Antropología de la Universidad Nacional de Córdoba. Los ejes eran los menhires - ahora en sus sitios de origen, en particular el de Casas Viejas - y el Conjunto Jesuítico de La Banda.

Desde el Estado provincial se tomarán medidas independientes -y hasta contradictorias- a las propuestas delineadas desde el ámbito científico. Por Ley ( $N^{\circ} 3.228$ / 1965) se promueve la creación del Parque Arqueológico de Tafí, a ser emplazado en la zona del Mollar, a los

\footnotetext{
19 Por Ley No 1829 se crea la villa veraniega de Tafí.

20 Capítulo VI, Apartado 7 de la Constitución Nacional de 1949.
}

fines de preservar las "reliquias arqueológicas de las civilizaciones indígenas". Unos años después se constituye la Comisión de Promoción del Parque Arqueológico del Menhir que, finalmente, solo logrará instalar algunos menhires en la Plaza de El Mollar.

La segunda mitad del siglo XX - más allá de los sucesivos golpes militares y lo que ellos implicaron para la sociedad tafinista, tucumana y nacional en general - puede ser caracterizada por la implementación de políticas económicas que apostarán fuertemente a la actividad turística en esta región del NOA. Quizás como una de las alternativas de estrategia de desarrollo económico frente a la debacle de la industria azucarera, el turismo fue ganando terreno en la provincia. En los comienzos de los setenta, bajo el gobierno del interventor provincial Sarrulle, se hace énfasis en el turismo con el objetivo de convertir a Tucumán en la capital del Norte Argentino por medio de la conquista de los cerros. Ésta se lograría con un plan caminero que, entre otros, uniría Raco con Tafí del Valle. El proyecto nunca se llevó a cabo, pero da cuenta de la relevancia de estos espacios en la política económica provincial. Durante la última dictadura militar se declara como "áreas turísticas" las localidades serranas de San Pedro de Colalao, Tafí del Valle, San Javier, Raco, entre otras ${ }^{21}$, en lento, pero contundente desmedro de su tradicional función agropecuaria.

La materialidad indígena prehispánica también irá formando parte de este proyecto y cada vez con mayor claridad irá configurándose como recurso económico. Gómez (1976), en su propuesta sobre la creación del Parque de los Menhires, señala la relevancia de ese tipo de evidencias por la atracción turística que ellos podían ejercer.

A fines de los 60 la titularidad del dominio público sobre las ruinas y yacimientos arqueológicos había pasado definitivamente del Estado Nacional a las jurisdicciones donde estos se encuentran ${ }^{22}$. Cada provincia pudo iniciar así una regulación propia, por medio de la gestión de los recursos arqueológicos que se hallan en su territorio. En la provincia de Tucumán fue la Ley № 4.593, promulgada durante la dictadura militar en el año 1976, la primera que norma legalmente su gestión. Más que garantizar su protección, el Estado se apropió del mismo ${ }^{23}$. Como una herramienta de manipulación patrimonial se procuró acopiar bienes históricos-arqueológicos para enriquecer los Museos Provinciales ${ }^{24} \mathrm{y}$ abrir centros de interés turístico.

Inicia así una etapa en la que se procura generar atractivos como, por ejemplo, con el Plan NOA Turístico

\footnotetext{
21 Ley provincial $4733 / 1977$.

22 Ley 17.771 (1968). Art. 2339 y 2340, Inc. 9 del Código Civil.

${ }^{23}$ Según el Artículo $1^{\circ}$, los sitios y vestigios arqueológicos constituyen propiedad exclusiva del Estado Provincial.

${ }^{24}$ Art. $5^{\circ}$ de la Ley $N^{\circ} 4.593$.
} 
-en función del evento mundialista futbolístico del '78 - y particularmente en Tucumán, con el Programa de Recuperación de Patrimonio Histórico Cultural de la Provincia. En ese marco el gobierno provincial firmó un convenio de cooperación científica y técnica con la Facultad de Filosofía y Letras de la UBA, que comprendía la "reconstrucción" de las "ruinas de Quilmes" y el traslado de los Menhires.

Como señala Endere (2000) es notable como esta legislación, promulgada durante el gobierno de facto de Bussi, hace énfasis en su interés turístico. Se va perfilando, así, uno de los mayores objetivos del patrimonio arqueológico actual.

Como bastión de enfrentamiento con la guerrilla a los inicios de la dictadura, se crea la Municipalidad de Tafí del Valle (MTV). Su primer intendente promovió la firma de un Convenio de Mutua Colaboración con la UNT a los fines de realizar estudios tendientes a la localización y posterior excavación de los yacimientos arqueológicos existentes en la circunscripción administrativa de la MTV. Con el material extraído se proponía crear un museo arqueológico que sirva como testimonio de las civilizaciones que tuvieron asiento en la zona y con la finalidad de "rescatar racionalmente el patrimonio nacional arqueológico". También se propuso avanzar en estudios que posibiliten la clasificación y consiguiente individualización de menhires emplazados en el parque del mismo nombre y los que existan en la zona. Este Convenio no se pudo llevar adelante por falta de recursos por parte de la Universidad. Los menhires quedaron supeditados a esta nueva exposición en un espacio distinguido del Valle (Manasse 1988), y totalmente desatendidos, al igual que el resto de las manifestaciones culturales prehispánicas de la región. Desatención que acompañó a la violencia, el atropello y la usurpación de un patrimonio que la gente de los valles no se cansa de reclamar desde la recuperación democrática.

\section{Construcción del patrimonio como recurso en democracia}

Con la recuperación de la democracia las tareas a encarar son muchas, duras y difíciles de abordar. La devastación tucumana acompaña la del resto de la nación, debiéndose aquí también revisar y delinear adecuadas políticas sociales y culturales. Se reanuda el debate sobre la definición y gestión del patrimonio cultural y, en particular del arqueológico, siendo Tucumán sede de las Primeras Jornadas de "Política Científica para la Planificación de la Arqueología en la Argentina" (1986). En ese marco, los científicos convocados expresaron su repudio al manejo incorrecto del patrimonio cultural prehispánico en los años previos en Tucumán, refiriéndose tanto a los menhires de Tafí, como al sitio de Quilmes ${ }^{25}$.

\section{También desde la población local comienza a expresarse}

${ }^{25}$ La Gaceta, edición del 14/10/1986; Clarín del 31/10/1986. finalmente el descontento con el manejo del patrimonio cultural. En 1989 los pobladores de Tafí presentan públicamente el reclamo titulado "Declaración de los Hombres del Mollar", por el cual solicitaban que se lleven a cabo las gestiones necesarias para la restitución de los menhires a su lugar de origen. Sin embargo, seguirán en la Loma por una década más. En los 90 se intentó valorizar a los menhires en su contexto; la declaración realizada por la Comisión Nacional de Museos y de Monumentos y Lugares Históricos en 1993 implica a los "asentamientos de menhires" de algunos sectores del Valle de Tafí26.

En el marco de la academia, el Instituto de Arqueología había renovado vínculos con la Facultad de Filosofía y Humanidades de la Universidad Nacional de Córdoba (1988), con el propósito de establecer líneas de cooperación centradas en el Valle de Tafí y orientadas a la gestión de su patrimonio cultural. Tras décadas de estudios, a cargo de Berberián, la gente del valle hoy cuenta con un Parque Arqueológico de carácter privado de acceso restringido (La Bolsa).

La constitución tucumana de 1990 declara que los valores arqueológicos e históricos constituyen parte del patrimonio cultural de la provincia, quedando bajo su protección más allá de su dominio (público o privado). Ello se ve reflejado en la Ley $N^{\circ} 7500$, que en 2005 deja sin efecto la ley de la dictadura y establece el carácter jurídico del Patrimonio Arqueológico como bienes muebles o inmuebles del dominio público provincial. La reforma constitucional tucumana del 2006, más allá de establecer que es el Estado (provincial y municipal) el que arbitrará los medios legales para proteger el Patrimonio, introduce elementos jurídicos novedosos que ya están plasmados en la Constitución Nacional de 1994, y que significan un cambio importante de perspectiva.

En general, las leyes no han reconocido los derechos de las poblaciones locales y de las comunidades indígenas. En este sentido, la promulgación de la Ley Nacional 25.517 (2001) ${ }^{27}$ significa un importante avance al respecto, en tanto cuente con la debida difusión en los espacios profesionales e institucionales correspondientes.

La ley provincial prevé la participación de representantes de las comunidades originarias y de las Instituciones Científicas en una Comisión Técnica ad hoc a los fines de considerar aquellas materias o áreas específicas

\footnotetext{
26 Ley Nacional No 24.262.

27 Esta Ley nacional -y su decreto reglamentario recientemente aprobado - reconocen y promueven la intervención de las comunidades en la gestión de los recursos culturales indígenas de sus territorios. Avanza sobre los derechos a la restitución de los restos mortales de aborígenes que formen parte de museos y/o colecciones públicas o privadas, a los pueblos indígenas que lo reclamen; por el otro, establece que para realizarse cualquier emprendimiento científico que tenga por objeto a las comunidades aborígenes, incluyendo su patrimonio histórico y cultural, se deberá contar con el expreso consentimiento de las comunidades interesadas. 1
} 
vinculadas a sus intereses (Art. $7^{\circ}$ ). Algo semejante ocurre con la Ley Provincial No 7801/2006 de declaratoria de Área Natural Protegida a los Valles del Tucumán ${ }^{28}$, que contempla la participación de un representante de las Comunidades Indígenas en lo que sería un Consejo Regional Permanente. Sin embargo, la falta de efectiva implementación de estas proposiciones, hacen nula sus intenciones.

Mientras tanto, partir de los 90 se retoman investigaciones arqueológicas en el área del montículo en Casas Viejas y se inician otras en la zona del Rincón ${ }^{29}$, del otro lado del valle comienza una vertiginosa intervención de rescate arqueológico para afrontar la creciente destrucción debida al desarrollo urbano de segundas viviendas. Sobre finales de esa década, desde la Escuela de Arqueología (UNCa), se logra un accionar científico más próximo a la gestión municipal (Manasse 2002 b).

El comienzo del tercer milenio es testigo de nuevos emprendimientos vinculados a la materialidad prehispánica en Tucumán. Con una intervención creciente del ámbito académico, articulando con las del Estado provincial en una gestión que cada vez se fue acercando más a la gente nativa de los lugares implicados, se abordan nuevos proyectos. Bajo el gobierno de Miranda, con una decisiva intervención del campo profesional universitario ${ }^{30}$, se termina desplazando los menhires del Parque de La Angostura al Mollar, al predio de la antigua Sala de lo que fuera la Estancia de los Frías Silva, hoy convertido en espacio público. En un acto de fuerte connotación política- se sacaron los primeros menhires un 24 de marzo, aniversario del cruento golpe militar de 1976.

También, poco tiempo después y frente a las continuas demandas por parte de la Comunidad India Quilmes y el apoyo explícito del Instituto de Arqueología (UNT), por la Ley $2723 / 3$ se rescinde el contrato para la explotación privada y se autoriza a la Secretaría de Turismo a llevar adelante la "recuperación" del Complejo Ruinas de Quilmes. Ese mismo año se había logrado su declaración como Lugar Histórico Nacional, dejando a un lado, a tono con las nuevas perspectivas adoptadas, la alusión con el apelativo de "ruinas" para referir a la "ciudad sagrada", perteneciente, ahora sí, a la Comunidad India Quilmes. La puja por los menhires, así como por la ciudad sagrada de Quilmes, continúa hasta el presente. Una lucha en la que intervienen voces diferentes, discursos más o menos expresos e intereses que llegan a ser contrapuestos. Tanto los primeros, como Quilmes, se fueron constituyendo en símbolos arqueológicos de lo que no debería haber pasado.

\footnotetext{
${ }^{28}$ Esta ley de declaratoria de Área Natural Protegida surgió como una inquietud de gran parte de la población de Tafí (Arenas, Manasse y Noli 2007).

29 Investigaciones a cargo de Núñez Regueiro y de García Azcárate respectivamente.

30 No sin conflictos, por lo complejo de una articulación con fuertes intereses políticos.
}

Como bien lo señalan Mastrángelo (2001) y, años más tarde, Endere (2007) o nosotros mismos (Manasse y Arenas 2001; Manasse 2008), los menhires se constituyeron en herramientas per se de configuración del pasado y presente tucumano, en un espacio ya tradicional de disputas políticas. Y, aunque podemos avizorar la más reciente participación de la población local, las decisiones finales están teñidas de intenciones e intereses políticos del Estado provincial y sus instituciones, pero, también, económicos por parte de los sectores empresariales. Estos últimos se hacen elocuentes en nuevos intentos de remover los menhires, esta vez para crear un "fantástico" calendario astronómico, para integrarlo, más allá de toda cuestión de tiempos, al circuito turístico del Qhapacñan, que tiene como punto de partida al Museo de Arqueología de Alta Montaña (MAAM) de Salta ${ }^{31}$.

\section{Re-semantización de la materialidad indígena}

A partir de la década de los noventa, más allá de las disputas recién señaladas, se están produciendo algunos cambios que merecen ser atendidos. La era menemista volvió a traer la explotación de los recursos como estrategia esencial de desarrollo (de algunos), transformándose, en no pocas oportunidades, en un verdadero expolio. La minería a cielo abierto es para el oeste argentino uno de los ejemplos más contundentes; pero, también, la explotación turística sin reparos, que va transformando el paisaje (natural y cultural) de modo tal de ofrecer "no lo que hay, sino lo que se quiere que haya..."32. Y, finalmente, el fenómeno de la urbanización de segundas residencias, que se articula con el negocio inmobiliario y con el movimiento de inversiones asociado al turismo nacional e internacional (Arenas, Manasse y Noli 2007).

En todos estos casos estamos hablando de la tierra, ese es el recurso último en juego; y en la tierra, los restos materiales del pasado prehispánico y colonial. Ya no solo menhires, sino todas aquellas materialidades que pertenecen a la historia indígena, que la configuraron y lo siguen haciendo en la actualidad.

Frente a estas nuevas coyunturas se observa una resemantización de los restos arqueológicos. A tono con la constitución de un sujeto colectivo con demanda de injerencia en la gestión y el dominio de los restos materiales indígenas - las propias comunidades - la materialidad de su pasado fue tomando otros sentidos ${ }^{33}$.

A través de los Estudios de Impacto Arqueológico (EIA), tanto frente a los grandes emprendimientos empresariales como a aquellos individuales, particulares, los restos arqueológicos (arqueológicamente definidos) se constituyen en frenos, obstaculizaciones a un avance

\footnotetext{
31 Proyecto Runi. 2010.

32 Cfr. Manasse y Camerlingo 2007.

33 Este tema es abordado en profundidad en Manasse (2008 a).
} 
bastante poco controlado. Aunque pueda parecer ciertamente contradictorio, en función de experiencias de otras regiones, en Tafí una parte importante de los resultados de los EIA son utilizados por las Comunidades Indígenas y por la población en general, para exponer y reclamar por sus derechos. No se trata de un trabajo "para" los nuevos propietarios de tierras; el recurso arqueológico se fue transformando en herramienta "para" la población local (Manasse y Arenas 2010). En el marco de una articulación de saberes que se está explorando desde el año 2006, comunidad indígena y científicos estamos apostando a la construcción de conocimientos necesarios en estas nuevas coyunturas (Manasse 2008 b).

\section{Consideraciones Finales}

Las materialidades del pasado de los pueblos indígenas de la región de los valles tucumanos han sido y son objeto de un complejo entramado de construcciones y políticas de gestión en las que intervienen distintos sujetos colectivos, con preeminencia del Estado en su configuración del plano jurídico. Su valor se deja entrever en la patrimonialización y en los diversos sentidos que fueron adquiriendo. Consideramos que los procesos intervinientes en la patrimonialización despliegan en su decurso histórico un entrecruzamiento en el cual el campo intelectual y académico muestra sus limitaciones.

Recursos identitarios para la construcción de la argentinidad, fueron herramientas para la creación de territorialidades provinciales, pero también indígenas, en tanto dibujaban sus espacios, sus tiempos, y, con ello, a su vez, sus derechos. Desde el aparato jurídico se apostó a este tipo de funciones a partir del momento en que se "apropió" y patrimonializó lo que para sus hacedores no es mero objeto, sino memoria..., y que implicó el despojo de sus recursos culturales. En el plano científico estas propuestas tienen su claro correlato en la monovocalidad de los discursos que se construyen y, más específicamente, en los supuestos de reemplazo poblacional, que partieron de la estigmatización de los pobladores de la época de la invasión española -así como de los coetáneos- o, directamente, de la negación de su existencia.

Recursos económicos después, su usufructo desde la explotación turística rebasó todo tipo de proyecciones desde el punto de vista científico, plasmándose como objetivo de importancia en la legislación vigente y, claro está, en las políticas implementadas desde el Estado provincial y nacional.

En los últimos tiempos observamos nuevas significaciones de estas materialidades indígenas, que compiten con las anteriores. También "recursos", ahora con mayor énfasis en un sentido cultural e identitario, pero a su vez claramente político como soporte jurídico del reclamo de derechos indígenas.

Sentidos que ponen en tela de juicio la autoridad que fuera delegada a los científicos, a los arqueólogos en particular, a la hora de dirimir el valor patrimonial de los restos del pasado prehispánico. Dejamos la puerta abierta para evaluar con mayor detenimiento estas y otras conceptualizaciones, que parecen superar las estrictamente académicas, arqueológicas. Entendemos que el sentido de este análisis no es menor, pues permite avanzar en el ámbito de las percepciones, legitimaciones, valoraciones y ausencias en el actual manejo de la materialidad indígena como recurso cultural.

Tafi del Valle y San Miguel de Tucumán, 15 de octubre de 2010.

\section{Agradecimientos}

Agradecemos a nuestros compañeros y compañeras de equipo de nuestro proyecto de investigación, con quienes trabajamos en forma conjunta en varios de los aspectos que pretendimos reflejar en este trabajo.

El presente trabajo se realiza en el marco de los Proyectos de Investigación CIUNT 26/G 428 "Producción y Gestión de Recursos Arqueológicos en el Valle de Tafí. Articulación ciencia y sociedad" y SECyT - UNCa 02/ B233 "Procesos socio - culturales del último milenio en el borde oriental del sub-área valliserrana: el Valle de Tafi'". (Dirección: Manasse).

\section{Bibliografía}

Ambrosetti, J. B. 1897 a. Los monumentos megalíticos del Valle de Tafí (Tucumán). Boletín del Instituto Geográfico Argentino. Tomo XVIII. Pp. $105-114$.

Ambrosetti, J. B. 1897 b. Por el Valle Calchaquí. Anales de la Sociedad Científica Argentina Tomo XLIV: 290 - 305.

Arenas, P. 1998. Alfred Metraux: momentos de su paso por la Argentina. Mundo de Antes 1:121 - 145.

Arenas, P. 1989-90. La antropología en la Argentina a fines del siglo XIX y principios del XX. RUNA 19: 147 160, Buenos Aires.

Arenas, P. 2003. De campesino a indio. Comunidades indígenas en la "puerta de los valles". Tafí del Valle, Tucumán, Argentina. Local, regional y global: prehistoria, protohistoria e historia en los Valles Calchaquíes, Anales Nueva Época, 6: 413-442, Cornell y Stenborg (eds.). Instituto Iberoamericano, Universidad de Göteborg.

Arenas, P., B. Manasse y E. Noli Comp. 2007. Introducción: paisajes y procesos en Tafí del Valle. Paisajes y procesos sociales en Tafí del Valle. Una mirada interdisciplinaria desde el Valle (Tucumán, Argentina) Edición de las Compiladoras. Pp. 9 - 44. San Miguel de Tucumán.

Barbieri de Santamarina, M. E. 1945 Antropogeografía del Valle de Tafí. Monografías del Instituto de Estudios Geográficos N 7 UNT.

Benavides, H. 2005. Los ritos de la autenticidad: 
indígenas, pasado y el estado ecuatoriano. Arqueología Suramericana/Arqueología Sul-amerciana 1 (1): 5 - 48. Eds.; C. Gnecco y A. Haber. Universidad del Cauca.

Bennett, W., E. Bleiler y F. Sommer. 1948. Northwest Argentine Archaeology. Yale University Press in Publications in Anthropology, No 38.

Bixio, B., E. Berberián. 1988. Modos de ocupación y explotación económica del Valle de Tafí en los siglos XVI y XVII. Sistemas de asentamiento prehispánicos en el Valle de Tafí. Ed. Comechingonia. Córdoba. 111 - 144

Bonfil Batalla, G. 1993. Nuestro patrimonio cultural: un laberinto de significados. El patrimonio cultural de México. Florescano, E. Comp. Fondo de Cultura Económica.

Borda, M. L. 1938 Tucumán indígena. Instituto de Historia, Lingüística y Folklore, UNT. Vol. II.

Bruch, C. 1911. Exploración arqueológica en las provincias de Tucumán y Catamarca. Biblioteca Centenaria. Tomo V. Universidad Nacional de La Plata.

Carrizo, S. 2010. Exploraciones arqueológicas en la construcción del territorio tucumano de fines del siglo XIX y principios del siglo XX. Historias de arqueología sudamericana. Nastri y Menezes Ferreira (eds.). Pp: 5576. Fundación Azara, Buenos Aires.

Carrizo, S. 2004. Inicios del Instituto de Antropología de la Universidad Nacional de Tucumán entre La Arqueología y la Etnología. Trabajo presentado al IV Encuentro Nacional y I Latinoamericano. La Universidad como Objeto de Investigación. Tucumán, Argentina. "90 Aniversario de la Universidad Nacional de Tucumán".

Curtoni, R. 2004. La dimensión política de la arqueología: el patrimonio indígena y la construcción del pasado. Aproximaciones contemporáneas a la Arqueología pampeana: Perspectivas teóricas, metodológicas, analíticas y casos de estudio. G. Martínez, M. Gutiérrez, R. Curtoni, M. Berón y P. Madrid (eds). Facultad de Ciencias Sociales, UNCPBA.

Endere, M. L. 2000. Arqueología y legislación en Argentina. Cómo proteger el patrimonio arqueológico. Serie Monográfica Nro. 1 INCUAPA. UNC.

Endere, M. L. 2002. Nuevas tendencias en materia de legislación provincial del patrimonio arqueológico en la Argentina. Anclajes. VI.6 Parte II (diciembre 2002): 295-327.

Endere, M. L. 2007. Management of Archaeological Sites and the Public in Argentina. BAR International Series 1708, Archaeopress, Oxford.

Endere, M. L., I. Podgorny. 1997. Los Gliptodontes son argentinos. La ley 9080 y la creación del Patrimonio Nacional. Ciencia Hoy Volumen 7 - N42 - Set/Oct 1997

Endere, M. L., R. Curtoni. 2003. Patrimonio, arqueología y participación: acerca de la noción de paisaje arqueológico. En: Análisis, Interpretación y Gestión en la Arqueología de Sudamérica. Curtoni y Endere Eds. 277 - 296.

Fabian, J. 1983. Time and the other. Nueva York. Columbia University.

García Canclini, N. 1992 Culturas hibridas. Estrategias para entrar y salir de la modernidad, Bs.As., Sudamericana

García Canclini, N. 1999 Los usos sociales del Patrimonio cultural. Ed. Criado, E. (coord) Patrimonio Etnológico. Nuevas perspectivas de estudio. Granada: Consejería de Cultura, Junta de Andalucía, pp. 16-33.

Gómez, R. 1976. Aportes para el parque Arqueológico de los Menhires (Tafí del Valle). Publicado en el año 1976 por la Facultad de Arquitectura y Urbanismo, UNT

González, A. R. 1989. El patrimonio cultural y la investigación en la Argentina. Antropología y Política Cultural. Patrimonio e Identidad. Ed. Ceballos Buenos Aires.

Lafone Quevedo, S. A. 1899. Viaje á los menhires é Intihuatana de Tafí y Santa Maria. Revista del Museo de La Plata. Vol XI: 121 - 128. La Plata

Mamani Condori, C. M. 1989 History and prehistory in Bolivia: what about the indians. Conflict in the archaeology of living traditions, editado por R. Layton, pp. 46-59. Unwin Hyman, Londres.

Manasse, B. 2002 a. Una historia alternativa sobre el pasado prehispánico de Tafí del Valle. Producciones Científicas NOA 2002 Congreso Regional de Ciencia y Tecnología NOA San Fernando del Valle de Catamarca.

Manasse, B. 1988. Propuesta de índole social para la legislación sobre protección del patrimonio arqueológico tucumano. Revista de Antropología Año III No.5

Manasse, B. 2002 b Convenio de Asesoramiento Arqueológico Municipalidad Tafí del Valle - Escuela De Arqueología (Unca). Simposio Recursos Culturales Arqueológicos: Legislación, Protección y Práctica Profesional. Actas XIII Congreso Nacional de Arqueología Argentina Tomo 2: 281 - 293. Editorial Brujas, Córdoba.

Manasse, B. 2006. Historias coloniales: la construcción del pasado tafinisto del siglo XVII. Aportes científicos desde Humanidades 6: 219 - 229. UNCa

Manasse, B. 2007. Tiempo antes de la conquista española en el Valle de Tafí... Paisajes y procesos sociales en Tafí 
del Valle. Una mirada interdisciplinaria desde el Valle (Tucumán, Argentina) Arenas, P. B. Manasse y E. Noli Comp. San Miguel de Tucumán. pp. 135 - 163

Manasse, B. 2008 a. Restos de Indios - Recursos Evidencias Ancestrales: sentidos de la materialidad prehispánica. IX Congreso Argentino de Antropología Social. Simposio: Patrimonio: conceptualizaciones y prácticas. Posadas. MS

Manasse, B. 2008 b Articulación de saberes: mapeando territorio indígena desde las evidencias del pasado. IX Congreso Argentino de Antropología Social, Posadas, Misiones. MS

Manasse, B. y P. Arenas. 2001. Los Recursos Arqueológicos: Conflicto e Intereses. (Tafí del Valle, Provincia de Tucumán, República Argentina). 5to. Congreso Internacional. Patrimonio Cultural. Contexto y Conservación. La Habana, Cuba. Editado en CD.

Manasse, B. y P. Arenas. 2010 Antropología y arqueología en contextos de nuevas luchas por la tierra. En: Arqueología, tierra y territorios: conflictos e intereses. Comp. Manasse y Arenas. Editorial Lucrecia. Pp. 13 - 52.

Manasse, B. y A. Camerlingo. 2007. Construyendo presente en el Valle de Tafí. Paisajes y procesos sociales en Tafi del Valle. Arenas, Manasse y Noli Comp. UNT pp. $449-462$.

Manasse, B. y A. Korstanje. 2009. Articulación academia - sociedad: el IAM en la gestión de los recursos culturales. Rastros en el Camino... Trayectos e Identidades de una Institución. Instituto de Arqueología y Museo IAM. Ed. EDUNT Comp. Arenas, Taboada y Aschero. En prensa.

Manasse, B. y M. Rabey. 1989/1992. El pasado en el conocimiento popular andino. Jornadas - Taller "El uso del Pasado" - Mesa Comunidad y Público. La Plata, Fac. de Cs. Naturales y Museo, U.N.L.P. Junio 1989.

Mastrángelo, A. 2001. Arqueología, tradición e identidad. La acción cultural sobre los menhires de la cultura Tafí Tafí del Valle - Tucumán - Argentina. Mundo de Antes $N^{\circ}$ 2: 119 - 135. Instituto de Arqueología y Museo (UNT).

Metraux, A. 1928. Plan acerca de la creación de un museo etnográfico en la provincia de Tucumán. Universidad de Tucumán (1939) Compilación de antecedentes desde su fundación hasta diciembre de 1936. Tucumán.

Montini, G. 2008. "Revalorizando Nuestras Raíces. Una Arqueología al Oeste del Valle de Las Carreras, Tafí del Valle, Tucumán". Trabajo final de la Carrera de Arqueología. Facultad de Ciencias Naturales e Instituto
Miguel Lillo, Universidad Nacional de Tucumán. (MS)

Ozslack, O. 1982 Reflexiones sobre la formación del estado y la construcción de la sociedad argentina. En Desarrollo Económico, n 84, vol. 21. IDES. Buenos Aires, pag. 531- 548

Patané Aráoz, Claudio J. 2009. Arqueología de los Encuentros. Lo Inka y lo Local en el Pukará de las Lomas Verdes (Tafí del Valle, Prov. de Tucumán, República Argentina). BAR, Izeta (ed.) Internacional Series 2025, South American Series $N^{\circ} 9$.

Podgorny, I. 2005. La mirada que pasa: museos, educación pública y visualización de la evidencia científica. História, Ciências, Saúde - Manguinhos, v. 12 (suplemento), p. 231-264.

Proyecto Runi. Calendario Andino. 2010. http://www. hlt.gov.ar/noticias/nota164.htm (Acceso 14 /06/ 2010).

Quiroga, A. 1899. Ruinas de Anfama. El pueblo prehistórico de La Ciénega. Boletín del Instituto Geográfico Argentino Tomo XX. Buenos Aires.

Quiroga, A. 1892. Calchaquí. Buenos Aires. TEA

Quiroga, A. 1898. Monumentos megalíticos de Colalao. Boletín del Instituto Geográfico Argentino. Tomo XIX. Fascículos 1-3.

Rodríguez, L. 2008. ¿Mestizos o indios puros? El Valle Calchaquí y los primeros antropólogos. Revista Avá Nº 13. http://www.scielo.org.ar/scielo. php?pid=S1851169420080002000048 script=sci_arttext (Acceso $16 / 06 / 2010)$

Santillán de Andrés, S. 1951. Poblaciones indígenas en el Valle de Tafí. Geographia una et varia UNT.

Scattolín, M. C. 2006 Categoremas indígenas y designaciones arqueológicas en el noroeste Argentino prehispánico. Chungara, Volumen 38, № 2: 185-196 Revista de Antropología Chilena

Schreiter, R. 1928 Monumentos megalíticos y pictográficos en los altivalles de la provincia de Tucumán. Boletín del Museo de Historia Natural. UNT. Tomo II No 1:1 - 9

Shanks, M. y C. Tilley 1992 Re-Constructing Archaeology. Theory and Practice. Routledge

Somonte, C. 2005. Uso del espacio y producción lítica en Amaicha del Valle (Departamento Tafí del Valle, Tucumán). Intersecciones en Antropología 6: 43-58. Facultad de Ciencias Sociales - UNCPBA - Argentina 